\title{
Bactericidal activity of PA-824 against Mycobacterium tuberculosis under anaerobic conditions and computational analysis of its novel analogues against mutant Ddn receptor
}

\author{
Sulochana Somasundaram ${ }^{1}$, Ramaian Santhaseela Anand ${ }^{2}$, Perumal Venkatesan ${ }^{3}$ and Chinnambedu N Paramasivan ${ }^{4^{*}}$
}

\begin{abstract}
Background: The resurgence of multi-drug resistant tuberculosis (MDR-TB) and HIV associated tuberculosis (TB) are of serious global concern. To contain this situation, new anti-tuberculosis drugs and reduced treatment regimens are imperative. Recently, a nitroimidazole, PA-824, has been shown to be active against both replicating and nonreplicating bacteria. It is activated by the enzyme Deazaflavin-dependent nitroreductase (Ddn) present in Mycobacterium tuberculosis which catalyzes the reduction of PA-824, resulting in the release of lethal reactive nitrogen species (RNS) within the bacteria. In this context, PA-824 was analyzed for its activity against latent tuberculosis under anaerobic conditions and compared with rifampicin (RIF) and pyrazinamide (PZA). Recent mutagenesis studies have identified A76E mutation which affects the above mentioned catalysis and leads to PA824 resistance. Hence, novel analogues which could cope up with their binding to mutant Ddn receptor were also identified through this study.

Results: PA-824 at an optimum concentration of $12.5 \mu \mathrm{g} / \mathrm{ml}$ showed enhanced bactericidal activity, resulting in $0 \mathrm{CFU} / \mathrm{ml}$ growth when compared to RIF and PZA at normal pH and anaerobic condition. Further docking studies revealed that a combinatorial structure of PA-824 conjugated with moxifloxacin (ligand 8 ) has the highest binding affinity with the wild type and mutant Ddn receptor.

Conclusions: PA-824 has been demonstrated to have better activity under anaerobic condition at $12.5 \mu \mathrm{g} / \mathrm{ml}$, indicating an optimized dose that is required for overcoming the detoxifying mechanisms of M. tuberculosis and inducing its death. Further, the development of resistance through A76E mutation could be overcome through the in silico evolved ligand 8.
\end{abstract}

Keywords: Bactericidal activity, Mycobacterium tuberculosis, Anaerobic activity, Docking, Ddn, PA-824

\section{Background}

It is estimated that one-third of the world's population is infected with $M$. tuberculosis and 8.7 million suffer from active TB and 1.4 million deaths occur due to it every year [1]. M. tuberculosis is able to evade the human immune response in part by triggering formation of insulating hypoxic granulomas following infection of pulmonary macrophages. Bacilli within this environment

\footnotetext{
* Correspondence: cn.paramasivan@finddiagnostics.org

${ }^{4}$ Foundation for Innovative New Diagnostics, Flat No. 6-14 (excluding No. 7), 9th floor, Vijaya Building, 17-Barakhamba Road, New Delhi 110 001, India Full list of author information is available at the end of the article
}

have adapted themselves to slowly replicate and respire, making them tolerant of many drugs. This resistant state is thought to contribute to the prolonged combination chemotherapy required to cure patients [2,3]. Lack of compliance with treatments lasting up to 9 months contributes to the emergence of resistant strains [4]. To contain this situation, new anti-tuberculosis drugs and lesser duration of treatment are of immediate requirement. The discovery of new drugs involves several constraints that discourage many companies from investing in novel anti-TB drugs. The research is expensive, slow and difficult, and it requires specialized facilities for 
handling M. tuberculosis. Application of bioinformatics in designing novel drugs to tackle intractable TB has become feasible [5]. PA-824 is a nitroimidazole, a class of novel anti-bacterial agents. As a potential TB therapy, it has many attractive characteristics including, its novel mechanism of action, its in vitro activity against all tested drug-resistant clinical isolates, and its activity both as a potent bactericidal and sterilizing agent in mice. In addition, the compound shows no evidence of mutagenicity in a standard battery of genotoxicity studies, no significant cytochrome P450 interactions, and no significant activity against a broad range of Gram-positive and Gram-negative bacteria [6]. Murine model and a pre clinical study showed a substantial activity on persisters $[7,8]$. These reasons necessitate us to characterize the in vitro activity of PA-824 under anaerobic conditions, a home for persisters. Further, an in silico derivative of PA-824 is proposed that could act under a key resistance mutation (A76E), attributed to cause PA-824 resistance in $M$. tuberculosis [9].

\section{Methods \\ Drugs}

PA-824 was provided by the Global Alliance for Tuberculosis Drug Development through Doris Rouse of Research Triangle Institute (Research Triangle Park, NC). PA-824 was prepared in Dimethyl Sulfoxide (DMSO); Pyrazinamide (PZA) (Sigma) in sterile distilled water and Rifampicin (RIF) (Sigma) in dimethyl formamide (DMF). They were sterilized by filtration through cellulose membranes with a pore size of $0.22 \mu \mathrm{m}$, and further dilutions were then made in sterile distilled water.

\section{In vitro oxygen depletion assay for $M$. tuberculosis}

The protocol used for the M. tuberculosis - in vitro oxygen depletion assay was a slight modification of the method described by Wayne and Hayes [10] and Wayne's Nonreplicating Persistence-2 (NRP-2) model [11]. Briefly, mid-log-phase aerobic M. tuberculosis $\mathrm{H} 37 \mathrm{Rv}$ cultures were prepared in $10 \mathrm{ml}$ of $7 \mathrm{H} 9$ liquid medium with Tween 80 -albumin-dextrose by inoculating M. tuberculosis $\mathrm{H} 37 \mathrm{Rv}$ and incubating at $37^{\circ} \mathrm{C}$ for $5-$ 7 days and the number of organisms were counted by using Thoma counter (Neubauer). Known volume $\left(10^{6}\right.$ organisms $/ \mathrm{ml}$ ) was inoculated into $18.6 \mathrm{ml}$ of Dubos medium at a normal $\mathrm{pH}$ in $28 \mathrm{ml}$ screw-cap McCartney bottles (universal containers) from Fishers Scientific Co Ltd., with methylene blue dye $(1.5 \mathrm{~g} / \mathrm{ml})$ as an indicator of oxygen depletion. The blue dye fades and finally disappears under anaerobic conditions, as described by Wayne and Hayes [10]. Two to three $\mathrm{mm}$ diameter hole was made on the lid with rubber septa, of the containers and the mouth was sealed with parafilm. The $\mathrm{H} 37 \mathrm{Rv}$ culture was grown at $37^{\circ} \mathrm{C}$ in an orbital shaker (Cetromat) at 1000 rotations $/ \mathrm{min}$ with slow stirring for 21 days. It was shaken steadily but not very actively, to keep the bacilli in suspension and to prevent from clumping. The culture was grown under closed caps with a limited headspace. After 21 days, $\mathrm{O}_{2}$ in the headspace was consumed and the bacteria were in a non-replicating and low metabolic state called NRP 2 stage. Then 0 day (Viable count) VC was set up on 7H11 agar plates and the drugs were added at different concentrations.

\section{Bactericidal action of the drugs}

PA-824 was injected at two different concentrations of $3 \mu \mathrm{g} / \mathrm{ml}$ (P1), $12.5 \mu \mathrm{g} / \mathrm{ml}$ (P2), and RIF \& PZA were injected at $1 \mu \mathrm{g} / \mathrm{ml}$ and $50 \mu \mathrm{g} / \mathrm{ml}$ respectively through the septa of 21-day-old cultures. Culture bottles were prepared in duplicates for each concentration of the drugs. The culture was removed by means of a syringe through the septa and the VC was set up on 2nd, 4th, 7 th, 10th, 14th, and 21st days. The cultures were serially diluted in saline and plated onto 7H11/OADC agar (Difco) plates in duplicates containing polymyxin B (200 $\mathrm{U} / \mathrm{ml})$, amphotericin B $(20 \mu \mathrm{g} / \mathrm{ml})$, carbenicillin $(100 \mu \mathrm{g} /$ $\mathrm{ml})$, and trimethoprim $(10 \mu \mathrm{g} / \mathrm{ml})$, to determine colonyforming unit (CFU) counts. The plates were placed in polythene bags, along with a plate inoculated with $\mathrm{Myco-}$ bacterium phlei and incubated at $37^{\circ} \mathrm{C}$. M. tuberculosis colonies were counted at $0,2,4,7,11,14$ and 21 days of incubation. The results were represented, as the mean of the quadruplicates of the cultures for every time point for every drug concentration and for the control cultures it was the mean of duplicates (Table 1).

\section{Statistics}

The results were expressed as the mean of the duplicates at each time point. Differences in the regression

Table 1 Bacterial count in $\log _{10} \mathrm{cfu} / \mathrm{ml}$ with standard deviation on different days

\begin{tabular}{cccccccc}
\hline Days & $\mathbf{0}$ & $\mathbf{2}$ & $\mathbf{4}$ & $\mathbf{7}$ & $\mathbf{1 1}$ & $\mathbf{1 1}$ & $\mathbf{1 4}$ \\
\hline No drug & $6.55 \pm 0.16$ & $6.68 \pm 0.23$ & $6.58 \pm 0.13$ & $6.28 \pm 0.23$ & $6.35 \pm 0.12$ & $6.37 \pm 0.09$ & $6.53 \pm 0.07$ \\
P1 $(3 \mu \mathrm{g} / \mathrm{ml})$ & $6.64 \pm 0.39$ & $6.45 \pm 0.08$ & $6.48 \pm 0.22$ & $6.21 \pm 0.19$ & $6.20 \pm 0.17$ & $5.62 \pm 0.54$ & $4.93 \pm 0.32$ \\
P2 $(12.5 \mu \mathrm{g} / \mathrm{ml})$ & $6.67 \pm 0.25$ & $5.44 \pm 0.44$ & $4.69 \pm 0.12$ & $4.18 \pm 0.41$ & $4.18 \pm 0.51$ & $4.15 \pm 0.09$ \\
RIF $(1 \mu \mathrm{g} / \mathrm{ml})$ & $6.93 \pm 0.04$ & $6.54 \pm 0.13$ & $6.62 \pm 0.05$ & $5.2 \pm 0.28$ & $5.35 \pm 0.06$ & $4.60 \pm 0.4$ \\
PZA $(50 \mu \mathrm{g} / \mathrm{ml})$ & $6.08 \pm 0.39$ & $6.84 \pm 0.02$ & $6.83 \pm 0.03$ & $6.30 \pm 0.13$ & $6.02 \pm 0.44$ & $6.33 \pm 0.3$ \\
\hline
\end{tabular}


coefficients of the log CFU counts with different drug combinations were tested by analysis of variance using test command in Stata, release 8 (Stata Corp, College station $\mathrm{Tx}$ ). The standard deviation (SD) of a result was obtained from the variation between CFU counts on the duplicate cultures, estimated separately for the log phase and the stationary phase cultures.

\section{Graphing}

No adequate representation on a logarithmic axis of the CFU count could be made of counts that yielded no colonies since $\log 0$ is minus infinity. A line was therefore drawn to extrapolate the values obtained at the two previous time points provided that it cut the $\mathrm{X}$ axis to the left of the time point yielding no colonies. Otherwise, the line was drawn through $\log 0$. In each case, the line concerned has been drawn dotted to indicate the uncertainty in its true position. Counts after the first negative count always failed to yield colonies, and their values have not been entered in the graphs.

\section{Docking tools}

The binding affinity of the analogues were obtained using AUTODOCK Vina tool with AMBER force field and Monte Carlo simulated annealing [12]. The dockings were performed in a 64 bit PC. The receptor design was made by using SWISS-MODEL, a fully automated protein structure homology-modeling server. In this tool, energy minimization and simulated annealing are done with the GROMOS96 forcefield [13]. The 2D structures of the ligands were drawn, optimized with full hydrogen bonds and saved as .sk2 format using ChemSketch tool from Advanced Chemistry Development, Inc. (ACD/ChemSketch, [14]) and the 3D structures were obtained using PRODRG server [15].

\section{Receptors}

The wild type receptor was derived from the crystal structure of deazaflavin dependent nitroreductase (3R5W) [16]. The mutant receptor was designed by introducing A76E mutation [9], in the sequence of Ddn and modeling it using SWISS MODEL without the presence of its cofactor F420.

\section{Ligands}

The ligands were derived from the structure of PA-824 by removing the trifluoromethyl group (CF3) and replacing it with key anti-M. tuberculosis drugs such as isoniazid, moxifloxacin, gatifloxacin etc., through ester linkages. The removal of trifluoromethyl group was done on the basis to reduce the toxicity [17]. The designed combinatorial ligands are listed in Table 2.

\section{Analysis of binding}

The binding sites for the docking were designed such that the entire receptor molecule was included within the selection grid. The highest binding energy values corresponding to the RMSD value of zero were considered as the binding affinity value of the ligands for each docking. The Hydrogen bond interactions were obtained using Molegro molecular viewer (molegro.com) [18].

\section{Results}

\section{Bactericidal activity}

The results of the bactericidal activity of different drugs from the two sets of experiments are given in Figure 1. PA-824 at lower concentration of $3 \mu \mathrm{g} / \mathrm{ml}$ (P1) had less activity on all the days resulting with a $\log$ of $4.9 \mathrm{CFU} /$ $\mathrm{ml}$ on the 21 st day. Rifampicin $(1 \mu \mathrm{g} / \mathrm{ml})$ showed slightly increased activity than PA-824 at a lower concentration of $3 \mu \mathrm{g} / \mathrm{ml}$, with a reduction in the count of $1.42 \mathrm{log}$ $\mathrm{cfu} / \mathrm{ml}$ on the 7 th day, whereas for PA-824 at a concentration of $12.5 \mu \mathrm{g} / \mathrm{ml}$ (P2), showed a decrease in the count to $\log$ of $2.49 \mathrm{CFU} / \mathrm{ml}$ on the same day. A small reduction in RIF activity was seen on the 7th day, and on 14th day reduction of $2.34 \mathrm{CFU} / \mathrm{ml}$ was observed and with no substantial change thereafter, whereas the activity of PA-824 at a concentration of $12.5 \mu \mathrm{g} / \mathrm{ml}$ continued to show a steady activity and resulted in a $0 \mathrm{CFU} / \mathrm{ml}$ on the 21st day. Since the experimentation was performed in non-acid condition, the activity of PZA was not efficient without any change in the $\log \mathrm{CFU} / \mathrm{ml}$ up to 21st day. Since PZA is not active in normal $\mathrm{pH}$ medium as it needs acidic environment for its action, our findings of low PZA activity in non-acidic $\mathrm{pH}$ fit with this established fact (Table 1).

\section{Docking studies}

The docking studies (Table 2) showed that Ligands 6 and 10 have the highest binding affinity of -8.4 and -8.0 $\mathrm{Kcal} / \mathrm{mol}$ respectively with the wild type Ddn receptor when compared to that of PA-824 which had a value of $-6.9 \mathrm{Kcal} / \mathrm{mol}$. Considering the mutant receptor, the binding of PA-824 was lowered to a value of $-6.7 \mathrm{Kcal} /$ mol showing that the active site mutation has a potential to lower the binding affinity. This trend was also followed in Ligands 6 and 10 whose binding affinity values were lowered to -8.1 and $-7.7 \mathrm{Kcal} / \mathrm{mol}$ respectively. Ligand 8, contradicted this trend showing an increase from $-7.7 \mathrm{Kcal} / \mathrm{mol}$ with the wild type receptor to a value of $-8.5 \mathrm{Kcal} / \mathrm{mol}$ with the mutant receptor. Considering that ligand 8 has a higher affinity to the wild type receptor itself than the PA-824, future evaluations of this lead could be effected. 


\begin{tabular}{ccccc}
\hline $\begin{array}{l}\text { S. } \\
\text { no. }\end{array}$ & Drug & $\begin{array}{c}\text { Docking score with wild type } \\
\text { receptor (kcal/mol) }\end{array}$ & $\begin{array}{c}\text { Docking score with A76E } \\
\text { mutant receptor (kcal/mol) }\end{array}$ \\
\hline 1 & $\mathrm{PA}-824$ & -6.9 & -6.7
\end{tabular}
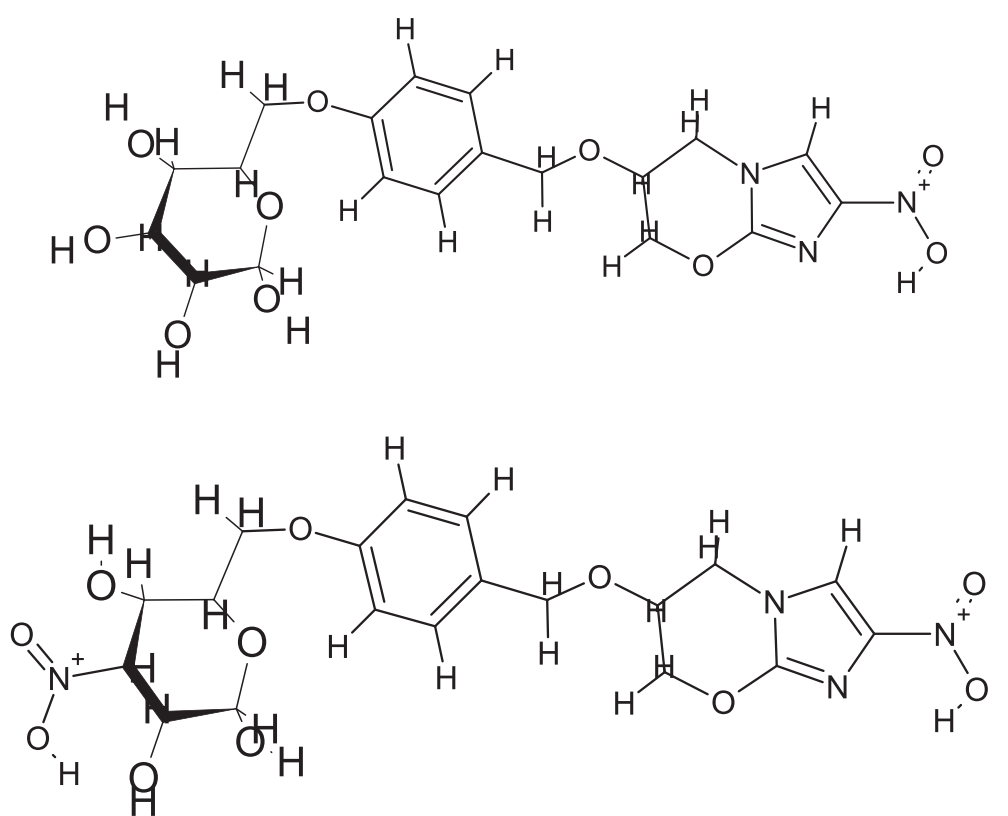

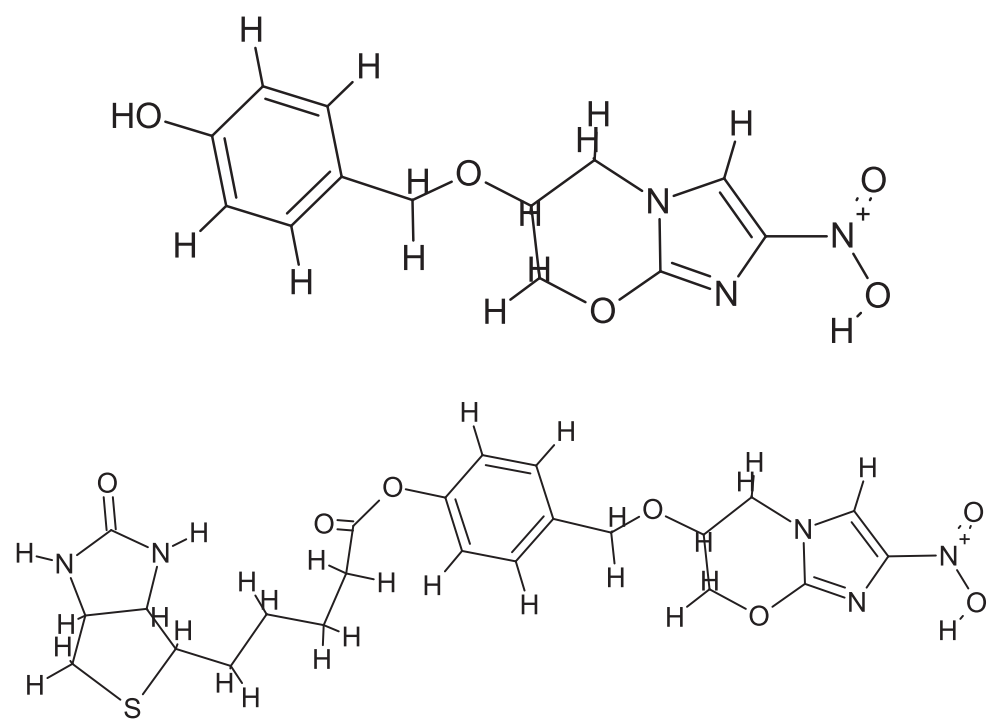

6 Ligand 5 (Cholestryl ester)

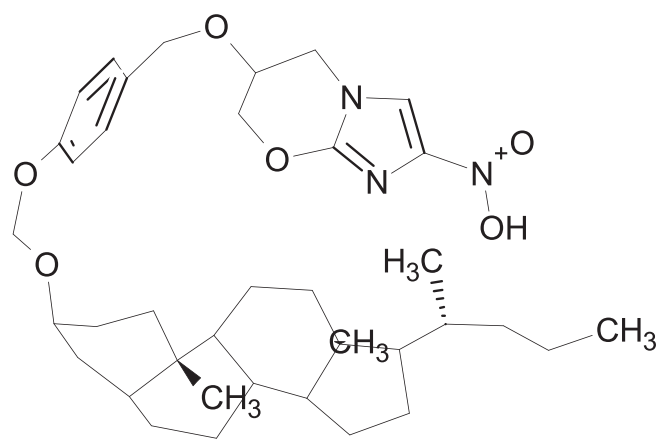

$7 \quad$ Ligand 6 (gati)
$-8.1$ 

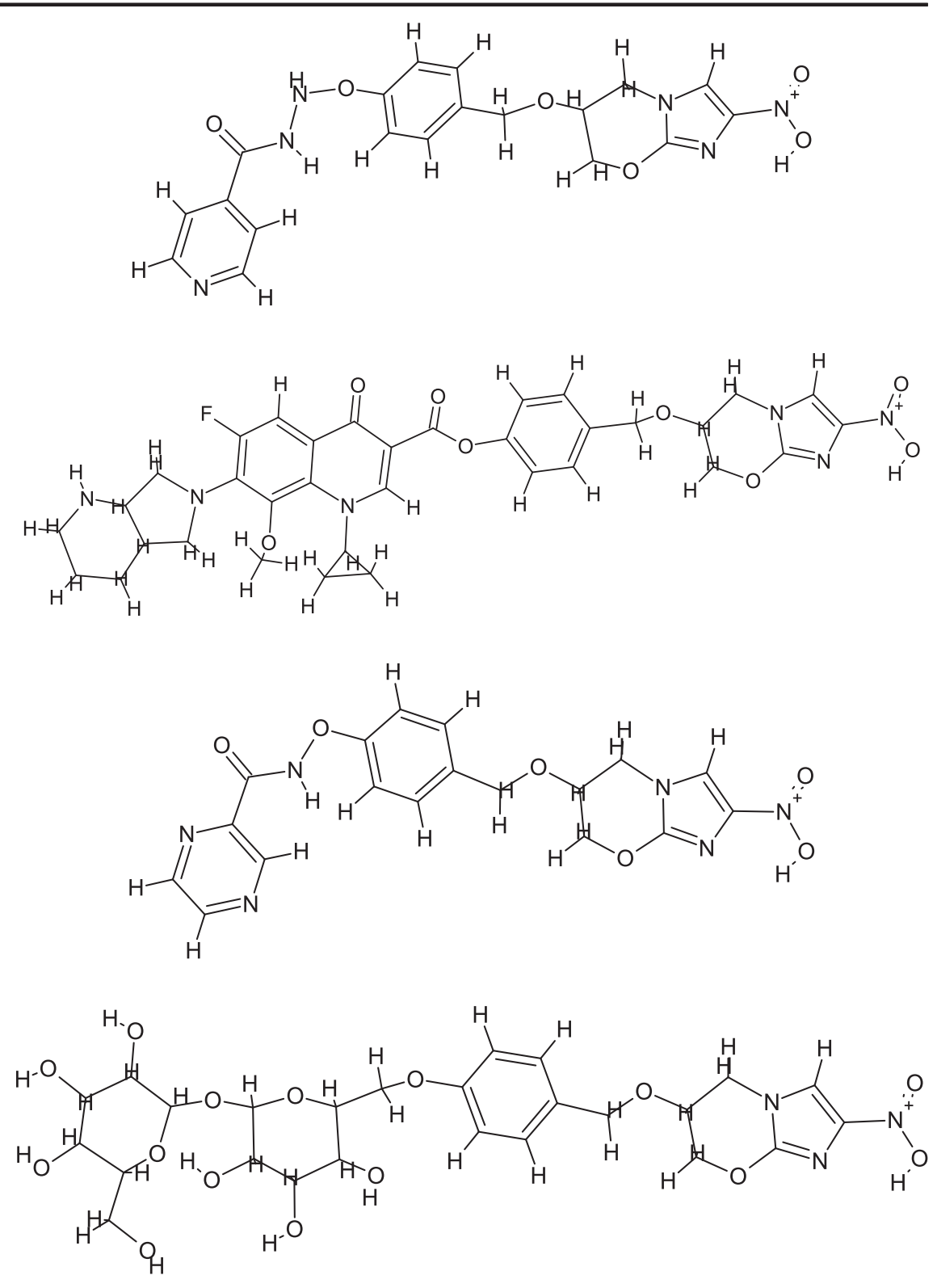


\section{Activity of PA824 in an anaerobic condition at normal \\ pH}

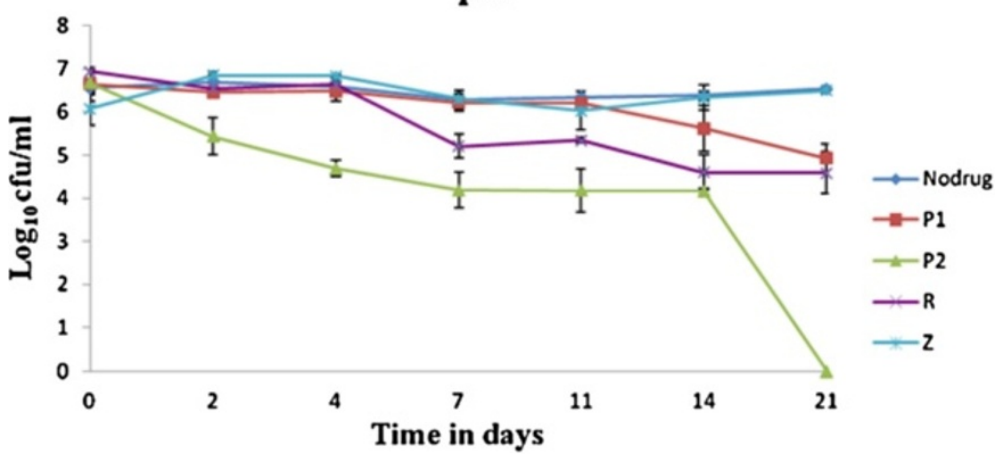

Figure 1 Bactericidal activity of PA-824 on Mycobacterium tuberculosis H37 RV under anaerobic condition. The treatment with $12.5 \mu \mathrm{g} / \mathrm{ml}$ of PA-824 shows a complete reduction in the log CFU/ml after 21 days. P1 and P2: PA-824 at 3 and $12.5 \mu \mathrm{g} / \mathrm{ml}$; R: Rifampicin at $1 \mu \mathrm{g} / \mathrm{ml}$; Z: Pyrazinamide at $50 \mathrm{\mu g} / \mathrm{ml}$.

\section{Discussion \\ Bactericidal activity}

The main aim of people, who are working for the control of tuberculosis, is to have a shorter treatment regimen than shorten the current six months duration. Following fluoroquinolones, few promising drugs were developed including nitroimidazo-oxazine PA-824, developed by Global Alliance for tuberculosis and which is in Phase II studies [7]. It has been shown that PA-824 has a novel mechanism of action affecting protein and lipid synthesis of M. tuberculosis and has potential bactericidal activity, which is comparable to that of isoniazid, a first line Anti-tuberculosis drug [8]. PA-824 also appears to be active against non-replicating bacilli, which suggests that it might be a potent sterilizing drug [19]. Hence the in vitro study was undertaken with PA824, to understand its bactericidal activity on static and anaerobic $M$. tuberculosis. After adaptation to micro aerophilic culture, the organisms do not multiply and the drugs that are capable of killing non-replicating bacteria are useful in treating latent infection with TB. This helps to determine the sterilizing activity on $M$. tuberculosis in our experiments with single drugs This study observed that the activity of PA-824 at the higher concentration of $12.5 \mu \mathrm{g} / \mathrm{ml}$, was greater than standard drugs such as RIF and PZA, which are known to have significant sterilizing activity (Table 1 and Figure 1).

Lenaerts et al., [20] showed that with 10ug/ml, PA-824 treatment under anaerobic conditions a reduction of $0.99 \mathrm{CFU} / \mathrm{ml}$, from 6.42 to $5.43 \mathrm{CFU} / \mathrm{ml}$ was observed at the end of 28 days ( 24 days of anaerobic culture +4 days of drug treatment), compared to $6.42 \mathrm{CFU} / \mathrm{ml}$ in the control. In our study, treatment with $12.5 \mu \mathrm{g} / \mathrm{ml}$ of PA824 showed a reduction to $4.69 \pm 0.12 \mathrm{CFU} / \mathrm{ml}$ from
$6.58 \pm 0.13 \mathrm{CFU} / \mathrm{ml}$ after 4 days of treatment, a net reduction of $1.89 \mathrm{CFU} / \mathrm{ml}$ which is higher than the reduction observed by Lenaerts et al., with $10 \mu \mathrm{g} / \mathrm{ml}$. Further, treatment with $2 \mu \mathrm{g} / \mathrm{ml}$ of PA-824 Lenaerts et al., [20] showed a reduction of $0.81 \mathrm{CFU} / \mathrm{ml}$ from 6.42 to $5.61 \mathrm{CFU} / \mathrm{ml}$ compared to control. In this study with $3 \mu \mathrm{g} / \mathrm{ml}$ of PA-824, a similar reduction of persisting $M$. tuberculosis count from $6.53 \pm 0.07$ to $4.93 \pm 0.32$ CFU/ $\mathrm{ml}$ (a reduction of $1.6 \mathrm{CFU} / \mathrm{ml}$ ) in 21 days was observed. This shows an approximate doubling of the killing activity $(0.81$ to $1.6 \mathrm{CFU} / \mathrm{ml})$ when the concentration and time are varied from $2 \mu \mathrm{g} / \mathrm{ml}$ (4 days) to $3 \mu \mathrm{g} / \mathrm{ml}$ (21 days). An increase in the treatment concentration to $50 \mu \mathrm{g} / \mathrm{ml}$ of PA-824 for 4 days in the study by Lenaerts et al., resulted in reductions to $5.24 \mathrm{CFU} / \mathrm{ml}$ whereas the treatment of $12.5 \mu \mathrm{g} / \mathrm{ml}$ of PA-824 for 21 days, which is a long term duration, resulted in complete reduction in the M. tuberculosis viable count. This could signify an important role of concentration and duration of PA-824 treatment that is required to control the persisting M. tuberculosis.

Considering the role of PA-824 as a NO donor, excess production of $\mathrm{NO}$ in the intracellular environment could fuel the growth of $M$. tuberculosis through its 'truncated hemoglobin' $\mathrm{N}$ (trHbN) detoxification machinery. In $M$. tuberculosis H37Ra, the activity of the glbN gene encoding $\operatorname{trHbN}$ is upregulated by the general nitrosative stress inducer, nitrite, by the NO releaser sodium nitroprusside and by hypoxia. The activity of the $g l b N$ gene is also enhanced during M. tuberculosis H37Ra invasion of THP-1 activated macrophages (producing NO) [21]. In in vivo, the high oxygen affinity of trHbN $\left(\mathrm{P}_{50} \sim\right.$ $0.01 \mathrm{~mm} \mathrm{Hg}$ ) may ensure a low but critical level of oxygen, granting survival of $M$. tuberculosis in the 
granuloma hypoxic environment when the bacilli enter latency [22]. It has been proposed that the oxygenated $\operatorname{tr} \mathrm{HbN}$ (oxy-trHbN) catalyzes the rapid oxidation of nitric oxide to innocuous nitrate with a second-order rate constant $\left(\mathrm{k}_{\mathrm{NOD}}^{\prime} \approx 745 \times 10^{6} \mathrm{~m}^{-1} \cdot \mathrm{s}^{-1}\right)$, which is 15 and 34 fold faster than the reaction of horse heart and sperm whale myoglobin, respectively $[23,24]$. The resulting nitrate, the most effective alternate terminal electron acceptor after molecular oxygen, could protect the $M$. tuberculosis from hypoxic, acid and RNS stress [25].

From crystallographic studies, it is proposed that residue Phe ${ }^{62}$ of trHbN exists in two conformations. In one, the benzene side chain of the residue blocks the longer channel of the tunnel path (the so-called closed state) and in the other it does not (the open state) $[26,27]$. By long Molecular dynamics (MD) simulations $(0.1 \mathrm{~ms})$, Bidon-Chanal et al. have proposed that in deoxytrHbN, the Phe ${ }^{62}$ adopts the closed conformation and hence the $\mathrm{O} 2$ ligand enters the protein via the short channel. In case of oxygenated trHbN, the $\mathrm{Phe}^{62}$ prefers the open conformation, thus facilitating the entrance of the second ligand (NO) via the long channel $[28,29]$. MD simulations [30] have revealed two additional tunnels: $\mathrm{EH}$ (EHT) and BE (BET). The conformational change from an open state to a closed state is more rare than the opposite, indicating the presence of a larger energy barrier for an open-to-closed transition. For the oxy-trHbN, the open state conformer is found $1.5 \mathrm{kcal} / \mathrm{mol}$ more stable than the closed conformer. The energy barrier for closed to open transition is $\sim 1.2 \mathrm{kcal} / \mathrm{mol}$ whereas the reverse energy barrier is $>3 \mathrm{kcal} / \mathrm{mol}$ [31]. Adding to this, trHbN matrix can hold more than one $\mathrm{NO}$ molecule at the same time. Further $\bullet$ NO diffuses from the bulk solvent through the channel to an internal cavity (EHc) of the trHbN molecule. This cavity is located between the tunnel (EHT) entrance and the side chain of the Phe ${ }^{62}$ residue. To reach EHc from the bulk, a NO must cross a bottleneck region of $1.3 \AA$ radius at the protein surface [30]. This could be favored by the presence of diffusion pressure under high NO concentrations generated by treatment with excess PA-824. Further excess production of NO in the intracellular environment could regulate autophagy, which is a host derived mechanism for the endocytosis of $M$. tuberculosis and killing it by fusion with lysosome $[32,33]$. Thus excess generation of NO itself could hinder the effectiveness of killing the bacteria.

This triggering of the detoxification machinery by NO highlights the importance of dose and treatment duration optimization in PA-824 therapy which could otherwise fuel the antioxidant survival strategies of $M$. tuberculosis outlined in the above discussion (Figure 2). This is also evident from the phase II clinical studies wherein increasing the PA-824 doses resulted in an unchanged Early bactericidal activity (EBA), with a steady decrease in the number of TB bacteria in the sputum ( $\sim 0.1 \log$ drop in CFU per day for 14 days, as compared

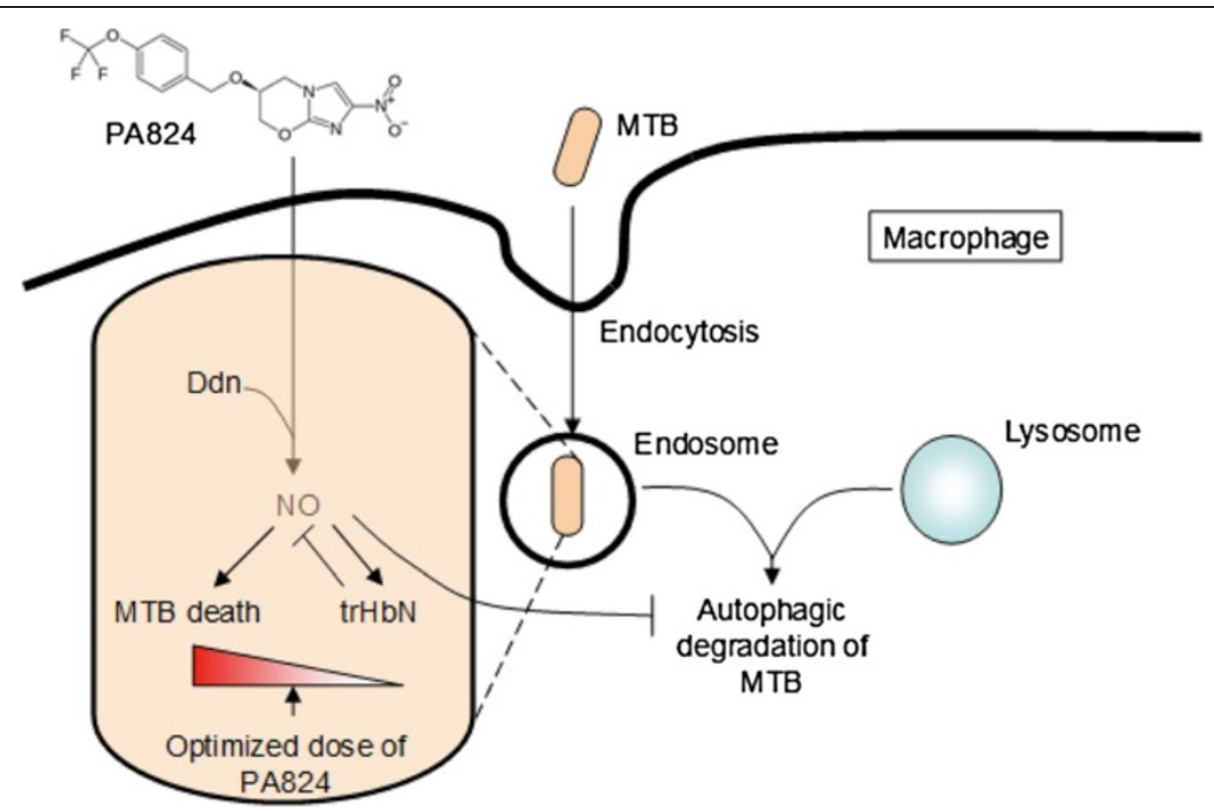

Figure 2 M. tuberculosis pathways associated with the dosage optimization for PA-824 treatment. Excess NO release during elevated PA824 concentrations could favor M. tuberculosis antioxidant defense mechanism involving trHbN and down regulation of autophagy. Hence dose optimization of PA-824 therapy is a key parameter for successful killing of the pathogen. 
with 0.148 for the standard regimen). This means that maximum effectiveness was seen at the lowest dose tested: $200 \mathrm{mg}$ [7]. The $12.5 \mu \mathrm{g} / \mathrm{ml}$ concentration of PA-824 and 21 days of treatment observed in this study could enhance the clearance of $M$. tuberculosis by overcoming its detoxification machinery. Thus the optimum dosage and treatment duration could provide better insights in setting the clinical evaluations using free drug concentration greater than MIC $\left(\mathrm{T}_{>\mathrm{MIC}}\right)$ as a parameter [34].

With respect to RIF, the findings of our study are similar to that of an in vivo model in mice, showing that PA824 was more active than RIF with more activity on the metabolically active organisms but not on nonreplicating organisms [20]. Since the culture is in a $\mathrm{pH}$ of 6.8 , as expected the PZA activity was constrained which has no bactericidal activity in non-acidic environments and the growth line in the graph (Figure 1) is similar to that of no drug. PZA had more sterilizing activity on slow multiplying organisms in an acidic condition inside macrophages [35], whereas PA-824 had more sterilizing activity on non-replicating persisters.

\section{Docking studies}

Interaction of PA-824 with the active site of wild type receptor show two hydrogen bond interaction of the imidazole nitrogen (Position 7) with the two hydroxyl groups of glutamic acid 83 represented in red (Figure 3). Interaction of PA-824 with the active site of mutant receptor shows a total of two hydrogen bonds. The oxygen of Nitro group interacts with Methionine 87 while the oxygen atom at position 8 interacts with Tryptophan 88 (Figure 4). These interactions show that the key hydrogen bonding with Glutamic acid 83 present in the wild type receptor is absent in the mutant receptor. Ligand 8, which showed a high affinity with the mutant receptor showed a different scenario of binding with three hydrogen bond interactions (Figure 5). The carbonyl oxygen showed interaction with Serine 78 (orange) and Lysine 79 (blue) and the oxazine oxygen showed interaction with Methionine 87 (yellow). The Serine 78 residue in the Ddn receptor is essential for the binding of F420, a cofactor involved in Ddn activity, and PA-824 [16]. Thus further investigation of the PA-824 binding in the presence of F420 cofactor needs to be evaluated. Interestingly, interaction of Ligand 8 with the wild type receptor showed no key hydrogen bond interactions. The presence of hydrophobic and electrostatic interactions could contribute to the better binding affinity value of $-7.7 \mathrm{kcal} / \mathrm{mol}$ (Figures 6 and 7 ).

Earlier in vitro and in vivo studies have shown an increased activity of moxifloxacin-conjugated dansylated carboxymethylglucan (M-DCMG) than free moxifloxacin against persisting $M$. tuberculosis within macrophages [36]. But this conjugation is not supportive for conjugation with PA-824 since Carboxymethylglucan has been shown to have antioxidant activities [37] which could counteract the essential ROS generation by PA-824 for bactericidal activity. Interestingly, it is also pointed that the efficacy of M-DCMG in improving the activity of Moxifloxacin [36] was that its ability to localize with the persisting tissues of $\mathrm{C} 57 \mathrm{BL} / 6$ mice infected with $M$. tuberculosis. Since PA-824 is known to localize to persisting tissues [19], its conjugation with moxifloxacin could provide a better therapeutic advantage against the persistors. Wang et al., [38] noted that fuoroquinolones such as moxifloxacin, appear to show enhanced action in the presence of ROS. This support the enhanced

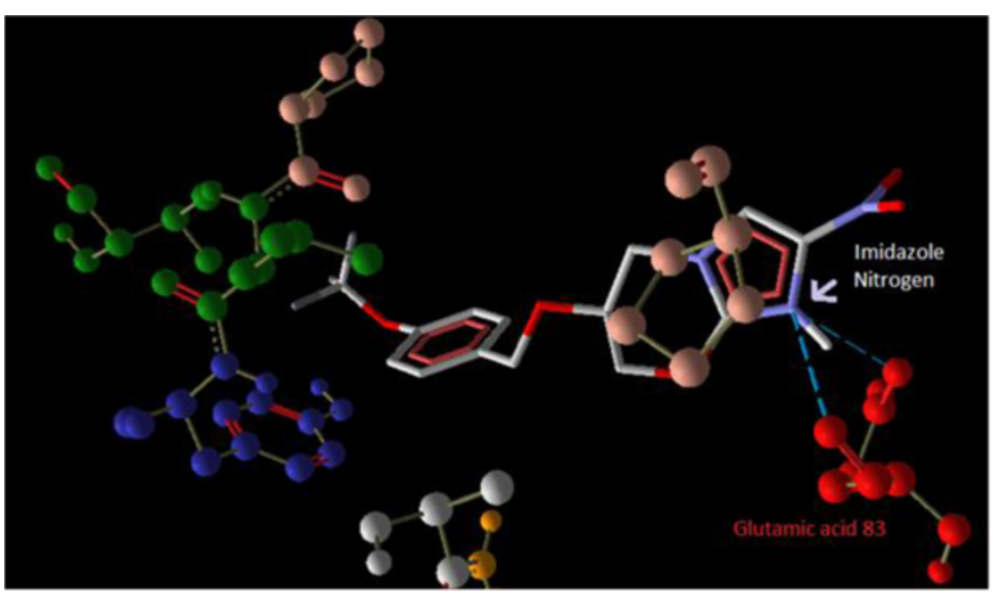

Figure 3 Interaction of PA-824 with the active site of wild type receptor show two hydrogen bond interaction (blue dotted lines) of the imidazole nitrogen (Position 7) with the two hydroxyl oxygens of glutamic acid 83 (red) of the Ddn receptor. 


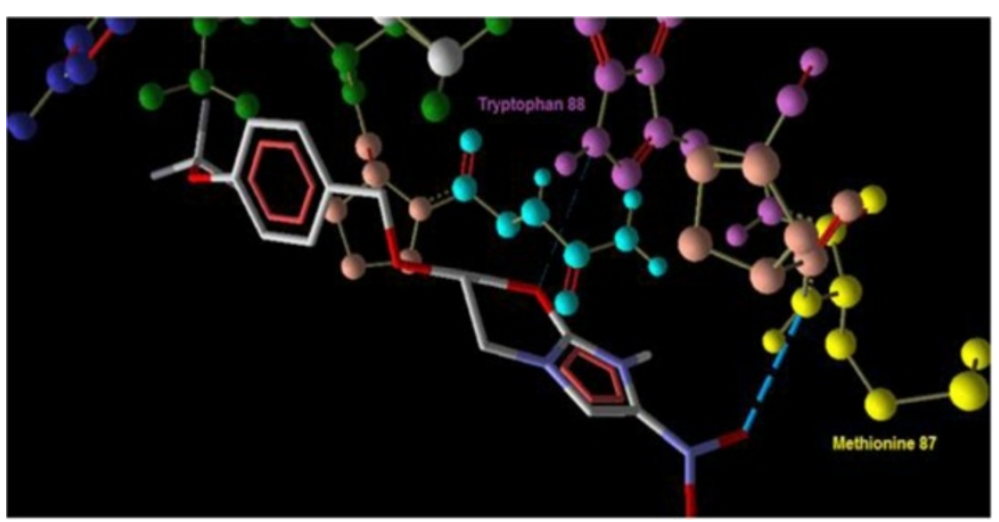

Figure 4 Interaction of PA-824 with the active site of mutant receptor shows the two hydrogen bonds (blue dotted lines). The oxygen of Nitro group interacts with Methionine 87 while the oxygen atom at position 8 interacts with Tryptophan 88 .

structure-activity relationship against $M$. tuberculosis by ligand 8 , which is a combinatorial structure of moxifloxacin with an ROS/RNS generator - PA-824. The support for the ester linkage for the structure activity of the combinatorial drug design is provided by the work by Georgopapadakou and Bertasso, [39], who showed that cephalosporin $3^{\prime}$-quinolone ester (Ro 23-9424) is effective in cases when neither of its individual components, cephalosporin and quinolone, are active. In the same way when there is resistance for moxifloxacin and PA-824 as individual drugs, the ester combination of both (ligand 8) could have a synergistic activity against $M$. tuberculosis which could help in combination therapy. Further, since ligand 8 showed binding at the hydrophobic pocket (red colour) of the Ddn receptor (Figure 6), it can be considered that the ligand has more of hydrophobic interactions. This feature could maintain the stability of the ester bond in the presence of plasma and esterases as described by Simões et al., [40]. A combination treatment of rifampin, moxifloxacin, amikacin and PA-824 has shown potent killing of MTB in vitro in 14 days [41]. Recently, another study of phase II clinical trials in South Africa, the combination therapy PaMZ, which consists of the novel TB drug candidate PA-824, moxifloxacin and pyrazinamide killed more than 99 per cent of people's TB bacteria within just 14 days and is potentially suitable for treating both drug sensitive and multidrug resistant tuberculosis [42]. Thus evaluation of treatment strategies applying combinatorial/synergistic activities could have a positive impact in the treatment of TB.

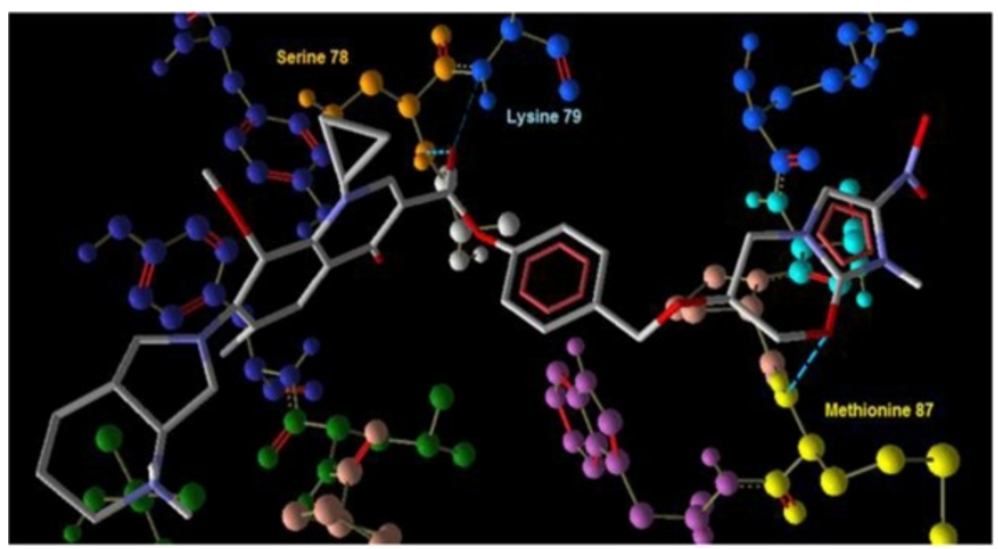

Figure 5 Interaction of ligand 8 (Moxi) with the active site of mutant receptor shows three hydrogen bond interactions (blue dotted lines). The carbonyl oxygen shows interaction with Serine 78 (orange) and Lysine 79 (blue) and the oxazine oxygen shows interaction with Methionine 87 (yellow). 


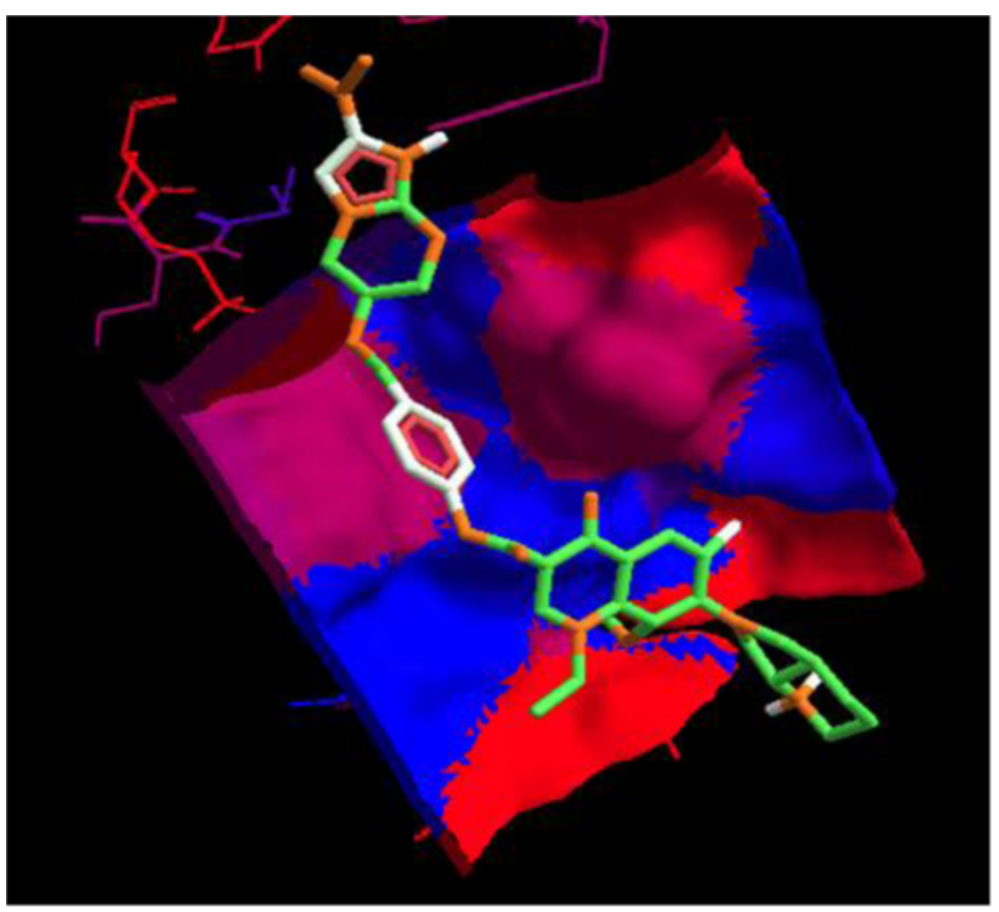

Figure 6 Interaction of ligand $\mathbf{8}$ with the wild type receptor showed no key hydrogen bond interactions. While the hydrophobicity of the binding pocket could contribute to the high binding affinity value of $-7.7 \mathrm{kcal} / \mathrm{mol}$.

\section{Conclusions}

In summary PA-824 exhibited greater bactericidal activity on non-replicating organisms (persisters) under normal $\mathrm{pH}$ than that of RIF and PZA, which may help in shortening the duration of treatment. Interestingly, the dose of $12.5 \mu \mathrm{g} / \mathrm{ml}$ and 21 days treatment was observed to have an ability to reduce the bacterial count to zero, which may offer key insights while setting the doses for in vivo/clinical studies. From the combinatorial analysis, ligand 8 (PA-824-Moxifloxacin ester conjugate) showed the most potent activity against both wild type and mutant Ddn receptors and hence needs further in vitro investigation of its enantiomeric binding properties with the Ddn receptor.

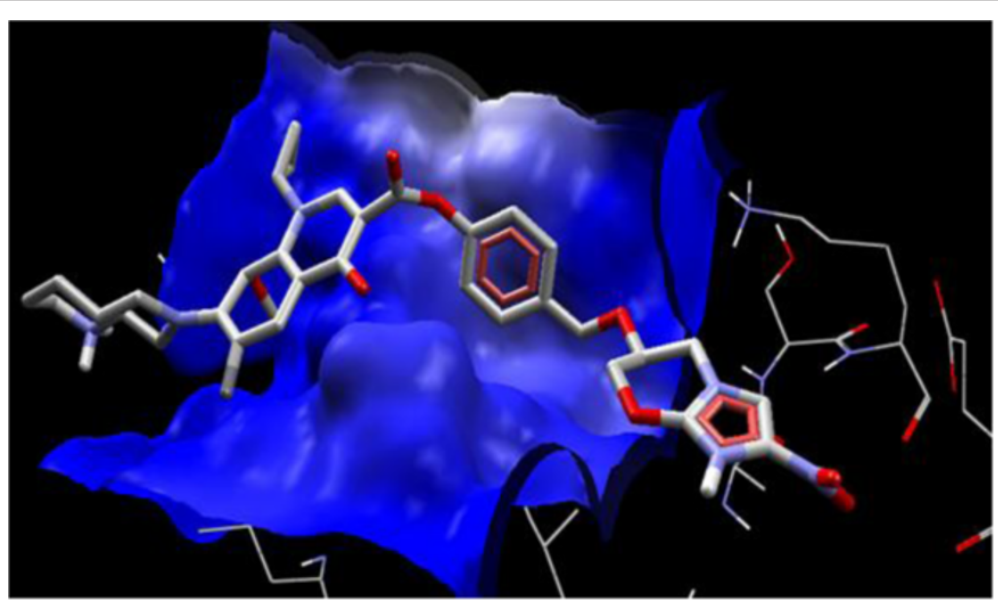

Figure 7 Ligand 8 electrostatic interaction with the active site of wild type receptor shows a favourable plateau of electrostatic interaction which could account for its binding affinity value of $-7.7 \mathrm{kcal} / \mathrm{mol}$. 


\section{Competing interests}

The authors declare that they have no competing of interests.

\section{Authors' contributions}

CNP, SS have designed the work. SS and RSA carried out the experiment. PV analyzed the data and contributed for the statistical analysis. SS and RSA wrote the manuscript and CNP reviewed the manuscript critically. All the authors have read the article and approved the final manuscript.

\section{Acknowledgement}

The authors thank the Director and the staff, National Institute for Research in Tuberculosis, Indian Council of Medical Research, Chennai for their valuable support with the conduct of wet lab experiments and the TB Global Alliance for supplying the PA-824 drug.

\section{Author details}

'Department of Biotechnology, Sri Venkateswara College of Engineering, Sriperumbudur, India. ${ }^{2}$ Centre for Biotechnology, Anna University, Chennai, India. ${ }^{3}$ National Institute for Research in Tuberculosis, Chennai, India. ${ }^{4}$ Foundation for Innovative New Diagnostics, Flat No. 6-14 (excluding No. 7), 9th floor, Vijaya Building, 17-Barakhamba Road, New Delhi 110 001, India.

Received: 12 February 2013 Accepted: 27 September 2013 Published: 1 October 2013

\section{References}

1. Global Tuberculosis Report: Global Tuberculosis Report. 2012. http://apps. who.int/iris/bitstream/10665/75938/1/9789241564502_eng.pdf.

2. Barry CE III, Boshoff HI, Dartois V, Dick T, Ehrt S, Flynn J, Schnappinger D, Wilkinson RJ, Young D: The spectrum of latent tuberculosis: rethinking the biology and intervention strategies. Nat Rev Microbiol 2009, 7:845-855.

3. Boshoff HIM, Barry CE III: Tuberculosis-metabolism and respiration in the absence of growth. Nat Rev Microbiol 2005, 3:70-80.

4. Sharma SK, Mohan A: Multidrug-resistant tuberculosis: a menace that threatens to destabilize tuberculosis control. Chest 2006, 130:261-272.

5. Kantardjieff K, Rupp B: Structural bioinformatic approaches to the discovery of new antimycobacterial drugs. Curr Pharm Des 2004, 10:3195-3211.

6. TB alliance: 2012. http://new.tballiance.org/new/portfolio/html-portfolioitem.php?id=18.

7. Diacon AH, et al: Early bactericidal activity and pharmacokinetics of pa824 in smear-positive tuberculosis patients. Antimicrob Agents Chemother 2010, 54(8):3402-3407.

8. Tyagi S, Nuermberger E, Yoshimatsu T, Williams K, Rosenthal I, Lounis N, Bishai W, Grosset J: Bactericidal activity of the nitroimidazopyran pa-824 in a murine model of tuberculosis. Antimicrob Agents Chemother 2005, 49(6):2289-2293.

9. Manjunatha UH, Helena B, Cynthia S, Dowd, Liang Z, Thomas J, Albert, Jason E, Norton, Lacy D, Thomas D, Siew Siew P, Clifton E, Barry: Identification of a nitroimidazo-oxazine-specific protein involved in PA824 resistance in Mycobacterium tuberculosis. PNAS 2006, 103(2):431-436.

10. Wayne $L G$, Hayes LG: An in vitro model for sequential study of shiftdown of Mycobacterium tuberculosis through two stages of nonreplicating persistence. Infect Immun 1996, 64(6):2062-2069.

11. Wayne LG: Synchronized replication of Mycobacterium tuberculosis. Infect Immun 1977, 17:528-530.

12. Trott O, Olson AJ, AutoDock Vina: Improving the speed and accuracy of docking with a new scoring function, efficient optimization and multithreading. J Comput Chem 2010, 31:455-461.

13. Arnold K, Bordoli L, Kopp J, Schwede T: The SWISS-MODEL workspace: a web-based environment for protein structure homology modelling. Bioinformatics 2006, 22:195-201.

14. ACD/Chemsketch Freeware, version 10.00. Toronto, ON, Canada: Advanced Chemistry Development, Inc; 2006. www.acdlabs.com.

15. Schuettelkopf AW, Aalten V: DMF: PRODRG - a tool for highthroughput crystallography of protein-ligand complexes. Acta Cryst 2004, D60:1355-1363.

16. Cellitti SE, Shaffer J, Jones DH, Mukherjee T, Gurumurthy M, Bursulaya B, Boshoff HI, Choi I, Nayyar A, Lee YS, Cherian J, Niyomrattanakit P, Dick T, Manjunatha UH, Barry CE 3rd, Spraggon G, Geierstanger BH: Structure of Ddn, the deazaflavin-dependent nitroreductase from Mycobacterium tuberculosis involved in bioreductive activation of PA-824. Structure 2012, 20(1):101-112.

17. Domagala J: Structure-activity and structure-side-effect relationships for the quinolone antibacterials. J Antimicrob Chemother Apr, 33(4):685-706.

18. Molegro molecular viewer - version 2.5.0. http://www.molegro.com/index.php.

19. Stover: A small-molecule nitroimidazopyran drug candidate for the treatment of tuberculosis. Nature 2000, 405:962-966.

20. Lenaerts AJ, Veronica G, Karen S, Marietta, Christine M, Johnson, Diane K, Driscoll, Nicholas M, Tompkins, Jerry D, Rose, Robert C, Reynolds, lan M, Orme: Preclinical testing of the Nitroimidazopyran PA-824 for activity against Mycobacterium tuberculosis in a series of in vitro and In Vivo models. Antimicrob Agents Chemother 2005, 49(6):2294-2301.

21. Pawaria S, Lama A, Raje M, Dikshit KL: Responses of Mycobacterium tuberculosis hemoglobin promoters to in vitro and in vivo growth conditions. App/ Environ Microbiol 2008, 74:3512-3522.

22. Couture M, Yeh S, Wittenberg BA, Wittenberg JB, Ouellet Y, Rousseau DL, Guertin M: A cooperative oxygen-binding hemoglobin from Mycobacterium tuberculosis. Proc Natl Acad Sci U S A 1999, 96:11223-11228.

23. Ouellet $H$, Ouellet $Y$, Richard C, Labarre M, Wittenberg B: Truncated hemoglobin $\mathrm{HbN}$ protects Mycobacterium bovis from nitric oxide. Proc Natl Acad Sci U S A 2002, 99:5902-5907.

24. Scott EE, Gibson $\mathrm{QH}$, Olson JS: Mapping the pathways for $\mathrm{O} 2$ entry into and exit from myoglobin. J Biol Chem 2001, 276:5177-5188.

25. Tan MP, Sequeira $P$, Lin WW, Phong WY, Cliff $P$, et al: Nitrate respiration protects hypoxic Mycobacterium tuberculosis against acid- and reactive nitrogen species stresses. PLoS One 2010, 5(10):e13356.

26. Milani M, Pesce A, Ouellet $Y$, Ascenzi $P$, Guertin M, Bolognesi M: Mycobacterium tuberculosis hemoglobin $\mathrm{N}$ displays a protein tunnel suited for $\mathrm{O}_{2}$ diffusion to the heme. EMBO J 2001, 20:3902-3909.

27. Milani M, Pesce A, Ouellet Y, Dewilde S, Friedman J, Ascenzi P, Guertin M, Bolognesi M: Heme-ligand tunneling in group I truncated hemoglobins. J Biol Chem 2004, 279:21520-21525.

28. Bidon-Chanal A, Martí MA, Crespo A, Milani M, Orozco M, Bolognesi M, Luque FJ, Estrin DA: Ligand-induced dynamical regulation of NO conversion in Mycobacterium tuberculosis truncated hemoglobin- $\mathrm{N}$. Proteins 2006, 64:457-464.

29. Bidon-Chanal A, Martí MA, Estrin DA, Luque FJ: Dynamical regulation of ligand migration by a gate-opening molecular switch in truncated hemoglobin-N from Mycobacterium tuberculosis. J Am Chem Soc 2007, 129:6782-6788.

30. Daigle R, Guertin M, Lague P: Structural characterization of the tunnels of Mycobacterium tuberculosis truncated hemoglobin N from molecular dynamics simulations. Proteins: Struct Funct Bioinf 2009, 75:735-747.

31. Mishra S, Meuwly M: Nitric oxide dynamics in truncated hemoglobin: docking sites, migration pathways, and vibrational spectroscopy from molecular dynamics simulations. Biophys J 2009, 96(6):2105-2118.

32. Sarkar S, Viktor I, Korolchuk, Maurizio R, Sara I, Angeleen F, Andrea W, Moises G-A, Claudia R, Shouqing L, Benjamin R, Underwood, Guido K, Cahir J, O'Kane, David C, Rubinsztein: Complex inhibitory effects of nitric oxide on autophagy. Mol Cell 2011, 43(1):19-32.

33. Ham H, Sreelatha A, Orth K: Manipulation of host membranes by bacterial effectors. Nat Rev Microbiol 2011, 9:635-646.

34. Ahmad Z, Peloquin CA, Singh RP, Derendorf H, Tyagi S, Ginsberg A, Grosset $\mathrm{JH}$, Nuermberger EL: PA-824 exhibits time-dependent activity in a murine model of tuberculosis. Antimicrob Agents Chemother 2011, 55:239-245.

35. Zhang Y, Mitchison D: The curious characteristics of pyrazinamide: a review. Int J Tuberc Lung Dis 2003, 7(1):6-21.

36. Schwartz: Novel conjugate of moxifloxacin and carboxymethylated glucan with enhanced activity against Mycobacterium tuberculosis. Antimicrob Agents Chemother 2006, 50(6):1982-1988.

37. Babincová: Antioxidant properties of carboxymethyl glucan: comparative analysis. J Med Food 2002, 5(2):79-83.

38. Wang X, Zhao X, Malik M, Drlica K: Contribution of reactive oxygen species to pathways of quinolone-mediated bacterial cell deat. J Antimicrob Chemother 2010, 65(3):520-524.

39. Georgopapadakou NH, Bertasso A: Mechanisms of action of cephalosporin 3 '-quinolone esters, carbamates, and tertiary amines in Escherichia coli. Antimicrob Agents Chemother 1993, 37(3):559-565.

40. Simões MF, Valente E, Gómez MJ, Anes E, Constantino L: Lipophilic pyrazinoic acid amide and ester prodrugs: stability, activation and activity against M. tuberculosis. Eur J Pharm Sci 2009, 37(3-4):257-263. 
41. Piccaro G, Giannoni F, Filippini P, Mustazzolu A, Fattorini L: Activities of drug combinations against mycobacterium tuberculosis grown in aerobic and hypoxic acidic conditions. Antimicrob Agents Chemother 2013, 57(3):1428-1433.

42. Andreas H, Diacon AH, Rodney D, Von Groote-Bidlingmaier F, Gregory S, Amour V, Donald PR: 14-day bactericidal activity of PA-824, bedaquiline, pyrazinamide, and moxifloxacin combinations: a randomised trial. Lancet 2012, 380(9846):986-993.

doi:10.1186/1471-2180-13-218

Cite this article as: Somasundaram et al:: Bactericidal activity of PA-824 against Mycobacterium tuberculosis under anaerobic conditions and computational analysis of its novel analogues against mutant Ddn receptor. BMC Microbiology 2013 13:218.

\section{Submit your next manuscript to BioMed Central and take full advantage of:}

- Convenient online submission

- Thorough peer review

- No space constraints or color figure charges

- Immediate publication on acceptance

- Inclusion in PubMed, CAS, Scopus and Google Scholar

- Research which is freely available for redistribution 